\title{
(6) OPEN ACCESS \\ Multi-country real-life experience of anti-vascular endothelial growth factor therapy for wet age-related macular degeneration
}

\author{
Frank G Holz, ${ }^{1}$ Ramin Tadayoni, ${ }^{2}$ Stephen Beatty, ${ }_{1}^{3}$ Alan Berger, ${ }^{4}$ Matteo G Cereda, ${ }^{5}$ \\ Rafael Cortez, ${ }^{6}$ Carel B Hoyng, ${ }^{7}$ Philip Hykin, ${ }^{8}$ Giovanni Staurenghi, ${ }^{5}$ \\ Stephanie Heldner, ${ }^{9}$ Timon Bogumil, ${ }^{10}$ Theresa Heah, $^{10}$ Sobha Sivaprasad ${ }^{8,11}$
}

\begin{abstract}
- Additional material is published online only. To view please visit the journal online (http://dx.doi.org/10.1136/ bjophthalmol-2014-305327)

For numbered affiliations see end of article.
\end{abstract}

Correspondence to Sobha Sivaprasad, King's College Hospital, Denmark Hill, London SE5 9RS, UK: senswathi@aol.com

Received 31 March 2014 Revised 9 July 2014 Accepted 16 August 2014 Published Online First 5 September 2014

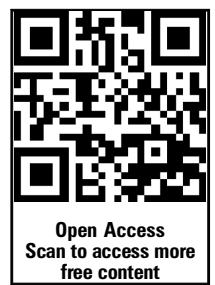

CrossMark

To cite: Holz FG,

Tadayoni R, Beatty S, et al. $\mathrm{Br} J$ Ophthalmol

2015:99:220-226.

\section{ABSTRACT}

Background/aims Real-life anti-vascular endothelial growth factor (VEGF) therapy use in patients with wet agerelated macular degeneration (WAMD) was assessed in a retrospective, observational study in Canada, France, Germany, Ireland, Italy, the Netherlands, UK and Venezuela. Methods Medical records of patients with WAMD, who started ranibizumab treatment between 1 January 2009 and 31 August 2009, were evaluated. Data were collected until the end of treatment and/or monitoring or until 31 August 2011.

Results 2227 patients who received $\geq 1$ anti-VEGF injection with a baseline visual acuity assessment and $\geq 1$ postbaseline visual acuity assessment for the treated eye were evaluated. Visual acuity improved until about day 120; thereafter, visual acuity gains were not maintained. Mean change in visual acuity score from baseline to years 1 and 2 was +2.4 and +0.6 letters, respectively. Patients received a mean of 5.0 and 2.2 injections in the first and second year, respectively. There were substantial differences in visual outcomes and injection frequency between countries. More frequent visits and injections were associated with greater improvements in visual acuity.

Conclusions In clinical practice, fewer injections are administered than in clinical trials. Anti-VEGF treatment resulted in an initial improvement in visual acuity; however, this was not maintained over time.

Trial registration number NCT01447043.

\section{INTRODUCTION}

Neovascular (wet) age-related macular degeneration (wAMD) is a progressive degenerative disease of the central retina. ${ }^{1}{ }^{2}$ The vascular endothelial growth factor (VEGF) antibody fragment ranibizumab was one of the first pharmacological agents proven to be beneficial in the treatment of wAMD.

Ranibizumab was approved for the treatment of wAMD based on results from two phase III trials: ANCHOR (patients with predominantly classic choroidal neovascularisation (CNV)) and MARINA (patients with minimally classic or occult CNV). ${ }^{3} 4$ Ranibizumab treatment resulted in improvements in visual acuity which were maintained with monthly treatment, resulting in visual acuity gains at month 12 of 8.5-11.3 letters in ANCHOR and 6.5-7.2 letters in MARINA. ${ }^{3}$

Monthly intravitreal injections are associated with a significant treatment burden for patients, caregivers and physicians, often making such a regimen unachievable in clinical practice. To reduce management burden, less frequent dosing regimens of ranibizumab (quarterly or pro re nata (PRN; as needed)) have been evaluated, but these usually have been associated with slightly less favourable outcomes than monthly dosing. ${ }^{5-7}$ In the HARBOR $^{\mathrm{i}}$ study, patients who received PRN treatment after three initial monthly doses had a numerically smaller gain in vision at month 12 than those continuing monthly treatment. ${ }^{8}$ However, the SUSTAIN $^{\mathrm{ii}}$ and IVAN ${ }^{\mathrm{iii}}$ studies indicated that efficacy outcomes could be achieved with less than monthly dosing. ${ }^{9}{ }^{10}$ A treat-and-extend regimen has also been used. ${ }^{11} 12$ In Europe, ranibizumab is licensed for monthly dosing until visual acuity is stable, followed by monitoring and resumption of treatment as needed. ${ }^{13}$ In the USA, ranibizumab once monthly is recommended; however, patients may receive three or four monthly doses followed by less frequent dosing with regular assessments. ${ }^{14}$

We report results from AURA ${ }^{\text {iv }}$, an international, retrospective study that assessed management of patients with wAMD receiving anti-VEGF treatment in clinical practice between 2009 and 2011.

\section{METHODS}

Study design

AURA was a retrospective, observational, multicentre study conducted in Canada, France, Germany, Ireland, Italy, the Netherlands, UK and Venezuela.

Patients with wAMD, who started treatment with ranibizumab between 1 January 2009 and 31 August 2009, were consecutively screened for eligibility. Written consent was obtained from each patient prior to inclusion where applicable. Approval from the relevant independent ethics

${ }^{\mathrm{i}}$ HARBOR (The pHase III, double-masked, multicenter, randomized, Active treatment-controlled study of the efficacy and safety of $0.5 \mathrm{mg}$ and $2.0 \mathrm{mg}$ Ranibizumab administered monthly or on an as-needed Basis (PRN) in patients with subfoveal neOvasculaR age-related macular degeneration).

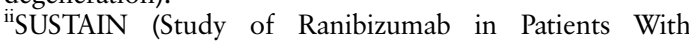
Subfoveal Choroidal Neovascularization Secondary to Age-Related Macular Degeneration).

iiiIVAN (A randomised controlled trial of alternative treatments to Inhibit VEGF in Age-related choroidal Neovascularisation).

${ }^{\text {iv }}$ AURA (A retrospective non-interventional study to assess the effectiveness of existing Anti-vascUlar endothelial growth factor [anti-VEGF] treatment Regimens in patients with wet Age-related macular degeneration). 
committees or institutional review boards and other national health authorities was received where required by local law and/ or regulations.

Patients participating in an investigational study of any other drug or device while using anti-VEGF therapy were excluded. Patients must have received $\geq 1$ ranibizumab injection to be included and were followed to the end of their treatment and/or monitoring or until 31 August 2011.

\section{Study endpoints}

The primary aim was to evaluate changes in visual acuity after the start of anti-VEGF therapy. Visual acuity was measured using Early Treatment Diabetic Retinopathy Study (ETDRS; equivalent notations) or Snellen (true Snellen fractions; where the numerator equals the test distance), depending on the centre. Thereafter, this was converted to the visual acuity scoring system (letter count; see online supplementary table S1).

Secondary objectives included determining anti-VEGF treatment regimens and disease monitoring in real-life settings.

Patients' medical records and results from examinations performed during routine practice were evaluated.

\section{Statistical analysis}

It was calculated that 399 subjects per country would be required to estimate the change from a baseline score in visual acuity based on the ETDRS letter score, with a 95\% probability of obtaining a CI with a width of not more than three letters. To allow for a $10 \%$ dropout rate, a sample size of 444 subjects per country was required.

Due to the exploratory nature of the study, all analyses are descriptive. The overall (exposed) population consisted of those who received $\geq 1$ dose of anti-VEGF treatment and the effectiveness analysis set consisted of patients who additionally had $\geq 1$ postbaseline assessment of visual acuity for the treated eye. The first-year and second-year completer analysis sets included those in the effectiveness analysis set for whom follow-up data for at least 1 and 2 years after first injection, respectively, were documented.

To account for missing data, mean change in visual acuity was assessed using a last observation carried forward (LOCF) analysis. Mean change in visual acuity from baseline was calculated at the first and second year of the study. Secondary outcomes were analysed by frequency tables or summary statistics by visit.

\section{RESULTS}

\section{Patients}

Overall, 2227 patients were included in the effectiveness analysis set (see online supplementary figure S1). Follow-up was documented for 1695 patients for at least 1 year after the first injection (first-year completers' set) and 1184 for at least 2 years after the first injection (second-year completers' set). Baseline characteristics were similar across the analysis sets (table 1 ).

\section{Visual acuity: change from baseline}

In the effectiveness analysis set, an improvement in visual acuity was observed until about day 120 (figure 1). Thereafter, visual acuity noticeably decreased. Similar results were observed in the first-year and second-year completers' sets. Mean change in visual acuity score from baseline to years 1 and 2 was +2.4 and +0.6 letters, respectively (effectiveness analysis set; LOCF analysis). In the first-year completers' set, changes in visual acuity from baseline to years 1 and 2 were +2.7 and +0.3 letters, respectively. In the second-year completers' set, changes in visual acuity from baseline to years 1 and 2 were +4.0 and +1.2 letters, respectively.

Patients who received an initial loading scheme (first three injections within 90 days) had greater improvements in visual acuity versus those who did not (figure 1), but the rate of decline in visual acuity thereafter did not seem associated with administration of loading doses. Baseline demographics were similar between patients who received loading doses and those who did not, including baseline visual acuity (data not shown).

Table 1 Patient demographics at baseline (all analysis sets)

\begin{tabular}{lllll}
\hline & Overall (exposed set) & Effectiveness analysis set & First-year completers' set & Second-year completers' set \\
\hline $\mathrm{N}$ & 2609 & 2227 & 1695 & 1184 \\
Age at diagnosis, years (mean \pm SD) & $76.8 \pm 8.4$ & $76.8 \pm 8.2$ & $76.7 \pm 8.0$ & $76.8 \pm 7.8$ \\
Age at treatment start, years (mean \pm SD) & $76.9 \pm 8.4$ & $76.9 \pm 8.2$ & $76.9 \pm 7.9$ & $77.0 \pm 7.8$ \\
Women, $\mathrm{n}(\%)$ & $1593(61.1)$ & $1349(60.6)$ & $1051(62.0)$ & $737(62.2)$ \\
Insurance ${ }^{*}, \mathrm{n}(\%)$ & & & \\
$\quad$ Public & $2214(84.9)$ & $1917(86.1)$ & $1472(86.8)$ & $1020(86.1)$ \\
Private & $183(7.0)$ & $162(7.3)$ & $102(6.0)$ & $64(5.4)$ \\
None & $186(7.1)$ & $126(5.7)$ & $109(6.4)$ & $86(7.3)$ \\
Other & $6(0.2)$ & $4(0.2)$ & 0 & 0 \\
$\quad$ Missing & $29(1.1)$ & $26(1.2)$ & $20(1.2)$ & $17(1.4)$ \\
Angiographic findings & $\mathrm{n}=1951$ & $\mathrm{n}=1708$ & $\mathrm{n}=1308$ & $\mathrm{n}=914$ \\
No CNV & $47(2.4)$ & $44(2.6)$ & $31(2.4)$ & $20(2.2)$ \\
Classic CNV & $550(28.2)$ & $473(27.7)$ & $344(26.3)$ & $219(24.0)$ \\
Classic and occult & $226(11.6)$ & $199(11.7)$ & $140(10.7)$ & $90(9.8)$ \\
Occult & $762(39.1)$ & $694(40.6)$ & $546(41.7)$ & $377(41.2)$ \\
Disciform scar & $11(0.6)$ & $9(0.5)$ & $4(0.3)$ & $2(0.2)$ \\
Unknown & $340(17.4)$ & $274(16.0)$ & $231(17.7)$ & $196(21.4)$ \\
Missing & $15(0.8)$ & $15(0.9)$ & $12(0.9)$ & $10(1.1)$ \\
Visual acuity, letters (mean \pm SD) & $\mathrm{NA}$ & $\mathrm{n}=2147$ & $\mathrm{n}=1642$ & $\mathrm{n}=1146$ \\
& & $55.4 \pm 18.4$ & $56.9 \pm 17.8$ & $57.2 \pm 17.9$ \\
\hline
\end{tabular}

*Multiple responses possible.

CNV, choroidal neovascularisation; NA, not available. 
Figure 1 Mean change in visual acuity score from baseline over time for all patients $(A)$, and according to loading scheme (B). Data based on effectiveness analysis set using a last observation carried forward (LOCF) approach.
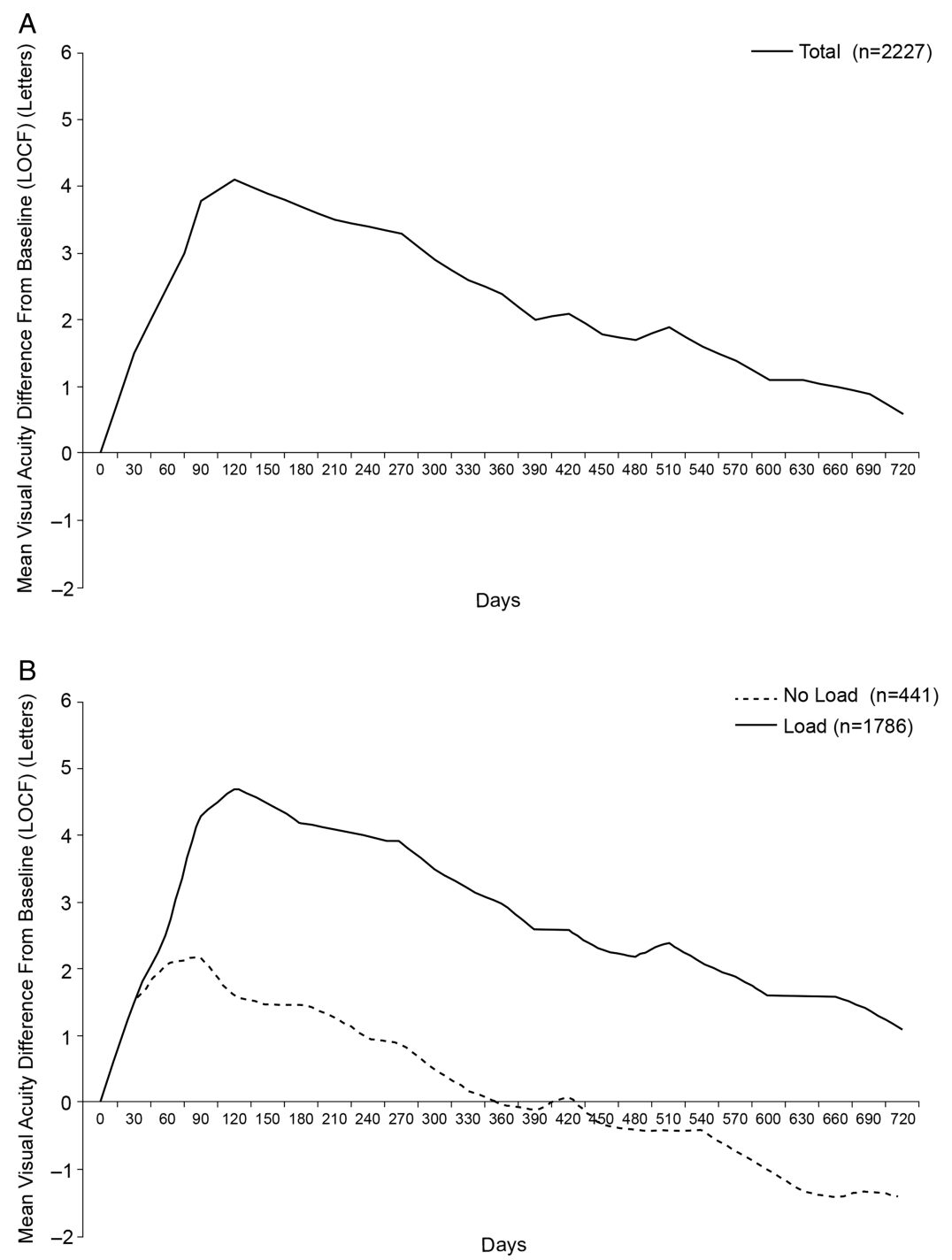

Visits, visual acuity tests and optical coherence tomographies (OCTs)

The mean number of patient visits was lower in the second year than in the first year (effectiveness analysis set: 8.6 and 4.9 visits, respectively). Similar results were seen in the first-year completers' set (9.5 and 6.4 visits, respectively) and second-year completers' set (9.8 and 7.5 visits, respectively).

This was also reflected in the number of performed visual acuity tests and OCTs. In the effectiveness analysis set, the mean number of visual acuity tests per patient was 6.0 and 3.8 in the first and second years, respectively. Similar results were seen in the first-year completers' set (6.7 and 5.0, respectively) and second-year completers' sets (7.2 and 5.9). The mean number of OCTs was 4.5 in the first year and 3.2 in the second year of the effectiveness analysis set. Similar results were seen in the first-year completers' set (5.2 and 4.3, respectively) and secondyear completers' set (5.8 and 5.1).

\section{Anti-VEGF injections}

Most patients in the effectiveness analysis set did not have any treatment changes during the study and received ranibizumab throughout. A minority of patients also received treatment with bevacizumab (141 patients) and pegaptanib (7 patients). In the full 2 years, patients received a mean of 7.2 anti-VEGF injections each in the effectiveness analysis set. In the first-year and second-year completers' sets, 8.4 and 9.1 injections, respectively, were received.

Patients received more anti-VEGF injections in the first year than the second year (effectiveness analysis set: mean of 5.0 and 2.2 injections, respectively). Similar results were observed in the first-year and second-year completer sets (5.5 and 2.9 injections in the first-year completers' set; 5.6 and 3.5 injections in the second-year completers' set).

\section{Reasons for ending the study}

A final visit before 31 August 2011 was documented in 68\% of the effectiveness analysis set. The main reason for ending the study was discontinuation of anti-VEGF therapy within the observation period (15.7\%). Other reasons included change of treating physician $(7.8 \%)$, patient withdrawal $(2.8 \%)$, loss to follow-up (3.1\%), patient death $(0.2 \%)$, unknown reasons $(1.3 \%)$ or other reasons $(1.1 \%)$.

For those who discontinued anti-VEGF therapy, the primary reasons, as determined by the treating physician, were stable disease within the observation period $(31.5 \%)$ or treatment failure $(23.2 \%)$. Other reasons included fibrosis/atrophic/scarring (8.9\%), patient's decision (4.0\%), ocular adverse event (3.2\%), cost/reimbursement issue $(2.0 \%)$, death $(0.3 \%)$ or other reasons $(12.6 \%)$. 
Table 2 Patient demographics at baseline per country (effectiveness analysis set)

\begin{tabular}{|c|c|c|c|c|c|c|c|c|}
\hline & Germany & France & UK & Italy & The Netherlands & Canada & Ireland & Venezuela \\
\hline $\mathrm{N}$ & 420 & 398 & 410 & 365 & 350 & 188 & 49 & 47 \\
\hline Age at treatment start, years $(m e a n \pm S D)$ & $\begin{array}{l}n=417 \\
76.7 \pm 8.2\end{array}$ & $\begin{array}{l}n=390 \\
77.5 \pm 7.7\end{array}$ & $\begin{array}{l}n=404 \\
77.7 \pm 7.5\end{array}$ & $\begin{array}{l}n=359 \\
75.2 \pm 7.7\end{array}$ & $\begin{array}{l}n=345 \\
77.2 \pm 9.1\end{array}$ & $\begin{array}{l}n=177 \\
79.8 \pm 7.8\end{array}$ & $\begin{array}{l}n=49 \\
72.7 \pm 10.6\end{array}$ & $\begin{array}{l}n=44 \\
73.1 \pm 9.8\end{array}$ \\
\hline Women, n (\%) & $251(59.8)$ & $241(60.6)$ & $247(60.2)$ & $212(58.1)$ & $220(62.9)$ & $114(60.6)$ & $36(73.5)$ & $28(59.6)$ \\
\hline Visual acuity, letters (mean \pm SD) & $\begin{array}{l}\mathrm{n}=416 \\
52.9 \pm 17.4\end{array}$ & $\begin{array}{l}n=381 \\
56.0 \pm 18.5\end{array}$ & $\begin{array}{l}\mathrm{n}=408 \\
55.0 \pm 17.8\end{array}$ & $\begin{array}{l}n=365 \\
65.5 \pm 15.0\end{array}$ & $\begin{array}{l}n=343 \\
50.1 \pm 19.0\end{array}$ & $\begin{array}{l}n=146 \\
47.2 \pm 18.8\end{array}$ & $\begin{array}{l}n=47 \\
64.7 \pm 14.1\end{array}$ & $\begin{array}{l}n=41 \\
48.3 \pm 19.4\end{array}$ \\
\hline
\end{tabular}

\section{Analysis by country}

Of the eight countries, five enrolled more than 400 patients and were evaluable for separate analysis (France, Germany, UK, Italy and the Netherlands).

Baseline characteristics were generally similar between countries; however, there were differences in baseline visual acuity (table 2 and see online supplementary figure S2).

Mean change in visual acuity score from baseline to years 1 and 2 differed between countries (table 3). In all countries, there was an initial improvement in visual acuity followed by a decrease in the visual acuity gains (figure 2). This decrease was least pronounced in the UK and the Netherlands, where there remained an improvement in visual acuity between baseline and year 2 . In contrast, there was a decline in mean visual acuity from baseline to year 2 in patients in Germany, France and Italy. Improvements in visual acuity between baseline and year 2 were also observed in Canada, Ireland and Venezuela, although caution should be used when interpreting these results due to low patient numbers.

In all countries, the mean number of visits was lower in the second year than the first year. However, the number of visits differed between countries. Patients in the UK had the highest number of visits (18.4 in the full 2 years). For other countries, the number of visits ranged from 8.3 (Venezuela) to 13.8 (Canada; table 3).

The number of anti-VEGF injections received differed between countries. Of the countries enrolling more than 400 patients, patients in the UK and the Netherlands had the highest number of injections.

\section{DISCUSSION}

In this retrospective study of real-life anti-VEGF therapy for wAMD between 2009 and 2011, visual acuity improved from baseline initially. Thereafter, a decline in visual acuity was observed, and the initial gain was not maintained. Patients visited their ophthalmologists more frequently during the first year and received more injections in the first year than in the second year. The use of a loading scheme appeared to be important for maximising the initial gain in visual acuity but did not seem to influence the rate of visual acuity decline during the full 2 years.

Our results are in line with other observational studies of ranibizumab use in clinical practice. In the LUMIERE study, which observed patients with wAMD who had received ranibizumab treatment for at least 12 months in France between September 2006 and October 2009, the mean change in visual acuity from baseline to month 12 was 3.2 letters and patients received an average of 5.1 injections. ${ }^{15}$ A smaller, retrospective chart review of patients treated in a French tertiary care centre showed that ranibizumab was associated with stabilisation of visual acuity, not with visual improvement. ${ }^{16}$

In the German WAVE study, a total of 3470 patients received ranibizumab. German guidelines recommend three monthly intravitreal injections, followed by a maintenance phase, where patients receive reinjections if signs of activity are noted. Patients received a mean of 4.34 ranibizumab injections in 12 months, and the mean change in visual acuity from baseline to month 12 was +0.02 logarithm of minimal angle of resolution. ${ }^{17} 18$

In a retrospective case review of 50 consecutive English patients with wAMD receiving treatment with ranibizumab on a PRN basis, patients were seen on average 11 times during the mean follow-up period of 13.6 months. Visual acuity at the end of follow-up improved by 4.6 letters from baseline, achieved with a mean of 4.7 injections per 12 -month period. ${ }^{19}$

The strengths of our study include the large sample size and the real-life assessment of anti-VEGF use, monitoring and visual

Table 3 Summary of resource utilisation and changes in visual acuity score from baseline per country (effectiveness analysis set)

\begin{tabular}{|c|c|c|c|c|c|c|c|c|c|}
\hline Country & $\mathrm{N}$ & $\begin{array}{l}\text { Mean overall } \\
\text { visits in full } \\
2 \text { years }\end{array}$ & $\begin{array}{l}\text { Mean performed } \\
\text { VA tests in full } \\
2 \text { years }\end{array}$ & $\begin{array}{l}\text { Mean performed } \\
\text { OCTs in full } \\
2 \text { years }\end{array}$ & $\begin{array}{l}\text { Mean } \\
\text { injections in } \\
\text { full } 2 \text { years }\end{array}$ & $\begin{array}{l}\text { Change in } \\
\text { VA score } \\
\text { to day } 90^{*}\end{array}$ & $\begin{array}{l}\text { Change in } \\
\text { VA score } \\
\text { to year 1* }\end{array}$ & $\begin{array}{l}\text { Change in } \\
\text { VA score } \\
\text { to year 2* }\end{array}$ & $\begin{array}{l}\text { Mean VA } \\
\text { score at } \\
\text { year } 2^{*}\end{array}$ \\
\hline \multicolumn{10}{|c|}{ Countries enrolling $>400$ patients } \\
\hline UK & 410 & 18.4 & 17.8 & 16.6 & 9.0 & 5.7 & 6.0 & 4.1 & 59.0 \\
\hline The Netherlands & 350 & 12.7 & 7.0 & 5.9 & 8.7 & 4.6 & 3.8 & 2.6 & 52.4 \\
\hline France & 398 & 13.4 & 9.2 & 9.1 & 6.3 & 4.1 & 0.8 & -1.1 & 54.4 \\
\hline Germany & 420 & 10.8 & 7.7 & 3.4 & 5.6 & 3.3 & 1.1 & -0.8 & 51.9 \\
\hline Italy & 365 & 12.7 & 6.5 & 4.9 & 5.2 & 1.4 & 0 & -2.9 & 62.7 \\
\hline \multicolumn{10}{|c|}{ Countries enrolling $<400$ patients } \\
\hline Ireland & 49 & 13.6 & NA & NA & 11.0 & 3.0 & 2.3 & 3.3 & 68.0 \\
\hline Canada & 188 & 13.8 & NA & NA & 9.9 & 4.0 & 3.2 & 1.6 & 46.5 \\
\hline Venezuela & 47 & 8.3 & NA & NA & 3.2 & 3.3 & 2.6 & 1.4 & 47.8 \\
\hline
\end{tabular}


Figure 2 Mean change in visual acuity score from baseline over time for all patients by country: Germany, France, UK, Italy and the Netherlands (A) and Canada, Ireland and Venezuela (B). Data based on effectiveness analysis set using a last observation carried forward (LOCF) approach.
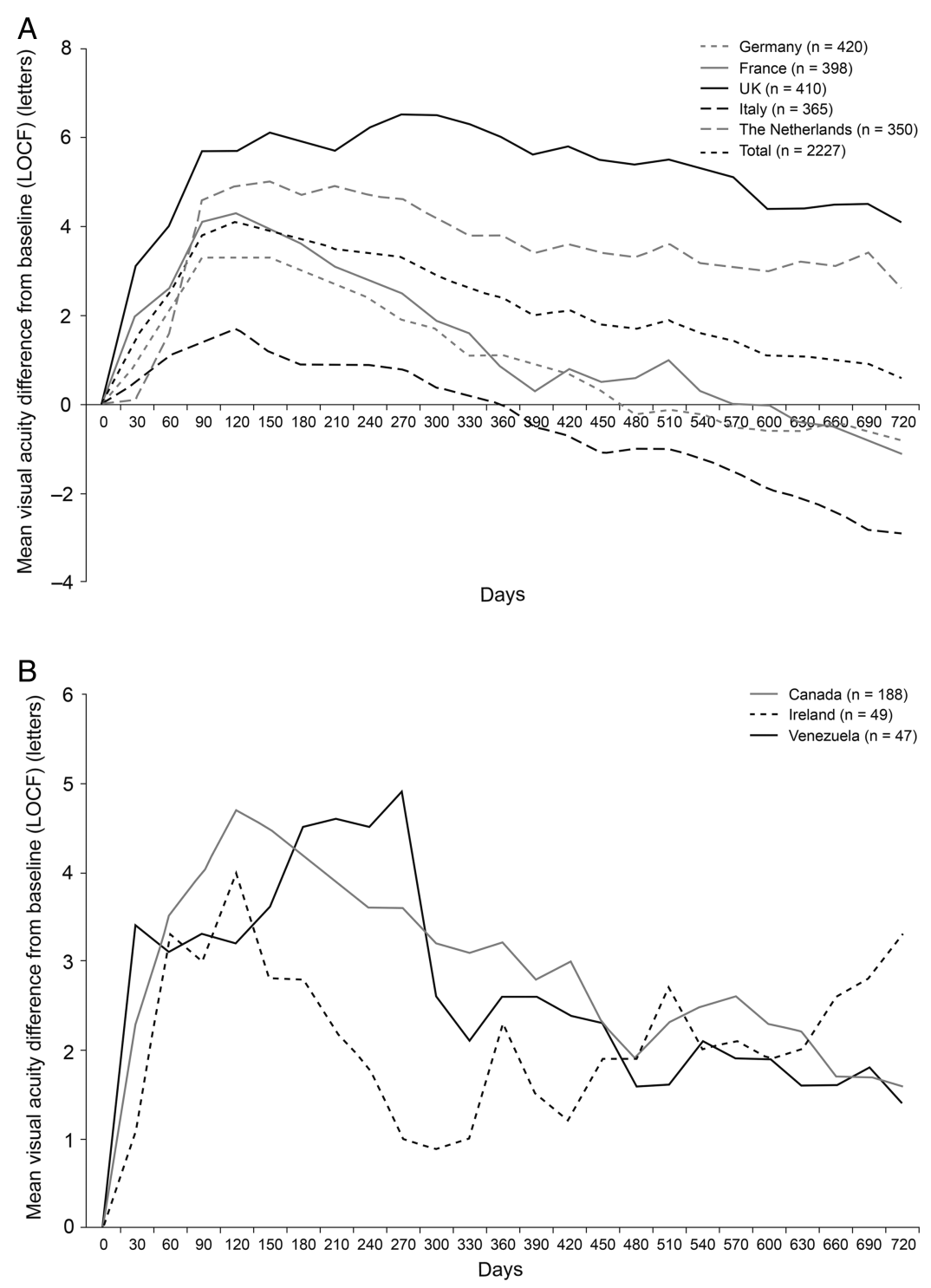

outcomes in consecutively enrolled patients across multiple centres and countries. The retrospective design prevented the investigator bias that may occur in prospective open-label studies. Our study is limited by the observational and uncontrolled nature of the design. In particular, our data reflect the documentation in the centres and therefore different patients contributed to the observed visual acuity data at each visit. The LOCF analysis that we, therefore, used to assess visual acuity changes over time led to a small downward shift of the visual acuity curves versus the observed values at each visit (see online supplementary Figure S3). Multiple centres per country were involved and included university hospitals and office-based physicians; however, it is uncertain whether the clinical centres included in AURA are fully representative of patient management in the entire country. For example, different retreatment criteria may have been used in different centres and there were some methodological limitations, such as different clinical centres used different OCT machines and the visual acuity score was translated into one common scale for analysis.

The number of visits, injections and visual acuity outcomes differed substantially between countries. Visual acuity outcomes, measured as change from baseline, may have been partly related to differences in baseline visual acuity and partly due to monitoring and treatment practices. For example, patients in the Netherlands had a lower baseline score (and thus more to gain), while patients in Italy had a higher baseline score and the low gain in visual acuity during the loading phase may have been due to a ceiling effect. However, maintenance of visual acuity gains was very different in countries with similar baseline visual acuity, for example, in the UK versus France. More visits and injections appeared to be correlated with more successful maintenance of visual acuity gains. The SEVEN-UP ${ }^{v}$ study, a noninterventional trial which evaluated outcomes 7-8 years after initiation of ranibizumab and included 65 patients originally treated with ranibizumab in the ANCHOR, MARINA and HORIZON studies had similar findings. ${ }^{20}$ A mean of 6.8 anti-VEGF injections had been received since exit from the HORIZON study (mean of 3.4 years) and while $43 \%$ of study eyes had stable or improved letter score versus ANCHOR/ MARINA baseline measurements, $34 \%$ had declined by $\geq 15$ letters. However, mean gain in letter score since exit from HORIZON was significantly better in patients who had received

vSEVEN-UP (Seven Year Observational Update of Macular Degeneration Patients Post-MARINA/ANCHOR and HORIZON Trials). 
$\geq 11$ anti-VEGF injections, suggesting vision may be partly related to injection frequency. ${ }^{20}$

The differences in disease management between countries are likely due to varying constraints and incentives associated with the healthcare systems within these countries, including reimbursement, selection of patients for treatment or the number of permitted injections. Further investigation of factors associated with improved visual outcome is required.

A substantial proportion of patients did not have complete follow-up for the full 2 years of the study, although this number varied considerably between countries. This highlights the need to ensure that patients continue to be monitored and receive appropriate treatment. The main reasons for discontinuing treatment in AURA were documented as stable disease or treatment failure, but as this was a retrospective analysis, detailed assessments of reasons for discontinuing treatment are limited.

Overall, we observed a good initial response to therapy, which then declined over time. Our results indicate that to achieve the best outcomes with ranibizumab, more frequent monitoring and injections may be needed. Ongoing research into treatment schedules and alternative therapies may help to reduce the trade-off between treatment burden and visual outcomes.

\author{
Author affiliations \\ ${ }^{1}$ Department of Ophthalmology, University of Bonn, Bonn, Germany \\ 2Department of Ophthalmology, Hôpital Lariboisière, AP-HP, Université Paris 7- \\ Sorbonne Paris Cité, France \\ ${ }^{3}$ Department of Ophthalmology, Institute of Eye Surgery, Waterford, Ireland \\ ${ }^{4}$ Department of Ophthalmology and Vision Sciences, University of Toronto, and St \\ Michael's Hospital, Toronto, Canada \\ ${ }^{5}$ Department of Biomedical and Clinical Science Luigi Sacco, Luigi Sacco Hospital, \\ University of Milan, Milan, Italy \\ ${ }^{6}$ Centro de Cirugia Oftalmologica, Caracas, Venezuela \\ 'Department of Ophthalmology, Radboud University Nijmegen Medical Centre, \\ Nijmegen, The Netherlands \\ ${ }^{8} \mathrm{NIHR}$ Biomedical Centre for Research in Ophthalmology, Moorfields Eye Hospital, \\ London, UK \\ ${ }^{9}$ Bayer HealthCare Pharmaceuticals, Berlin, Germany \\ ${ }^{10}$ Bayer HealthCare Pharmaceuticals, Montville, New Jersey, USA \\ ${ }^{11}$ King's College Hospital, London, UK
}

Acknowledgements The authors would like to thank Andreas Altemark of Bayer HealthCare Pharmaceuticals for his contribution to the design of the study protocol and participation in discussions on the interpretation of the data included in the manuscript. PH and SS would like to thank NIHR Moorfields Biomedical Research Centre for their support in conducting the study. All data management-related activities for the AURA study were coordinated and overseen by Anja Laske and Joachim Kosuch at Bayer Pharma. All statistical-related activities for the AURA study were coordinated and overseen by Claudia Tueckmantel at Bayer Pharma. The contract research organisation Kantar Health $\mathrm{GmbH}$ (Munich, Germany) was responsible for the data management system, data management, quality review, statistical analysis and report writing. The authors take full responsibility for the scope, direction and content of the manuscript and have approved the submitted manuscript. Medical writing assistance was provided by Caroline Allinson of PAREXEL and was funded by Bayer HealthCare Pharmaceuticals.

Contributors $F G H, R T, S B, A B, M G C, R C, C B H, P H, G S$ and $S S$ are members of the Global Steering/Publication Committee for the AURA study and have been responsible for and/or involved in provision of patients/data acquisition, data analysis, data review and interpretation. SH was responsible for the global study management and for the supervision of the set-up and conduct of the study. TH was the sponsor study physician adviser and has contributed to the study concept, data analysis and interpretation. TB has contributed to the study concept, data analysis and interpretation. All authors provided critical review of the manuscript and approved the final version for publication.

Funding The AURA study was funded by Bayer HealthCare Pharmaceuticals AG, Leverkusen, Germany. The funding organisation participated in the design and conduct of the study, analysis of the data and preparation of the manuscript.

Competing interests FGH is a consultant to Acucela, Genentech, Novartis, Bayer HealthCare, Alcon, OPTOS, Heidelberg Engineering, Carl Zeiss Meditec, Allergan and Pfizer and has received grants from OPTOS, Heidelberg Engineering, Carl Zeiss Meditec, Alcon, Genentech, Bayer HealthCare and Novartis. RT is a board member of Alcon, Novartis, Allergan, Bausch \& Lomb, Pfizer, Alimera, Bayer HealthCare and FCl-Zeiss and a consultant for Allergan, DORC, Alcon, Novartis, Takeda, Bausch \& Lomb and FCl-Zeiss. He has received payment for lectures from Alcon, Bausch \& Lomb, Novartis, Allergan, Pfizer, Takeda, Bayer HealthCare and Alimera and has received payment for the development of educational presentations from Bausch \& Lomb, Novartis, Zeiss, Sony, Alcon and Allergan. He has also received support for meeting expenses (travel and accommodation) from Alcon, Novartis, Allergan, Bausch \& Lomb, Pfizer, Bayer HealthCare, DORC, Takeda, Servier and Alimera. SB is a consultant and board member for Bayer HealthCare and has received support for travel to meetings and fees for participation in review activities from Bayer HealthCare. $A B$ is a consultant to Bayer HealthCare and has received travel support and fees for participation in review activities from Bayer HealthCare. He has also received payment for lectures from Bayer HealthCare. MGC is a consultant to Bayer HealthCare and has received support for travel to meetings from Bayer HealthCare. $\mathrm{RC}^{\prime}$ 's institution has received an honorarium from Bayer HealthCare. $\mathrm{CBH}$ is a consultant to Bayer HealthCare. PH has received grants from Bayer HealthCare, Allergan and Novartis and acts as a consultant to Bayer HealthCare, Novartis and Allergan. He has also received support for travel to meetings, for participation in review activities and provision of writing assistance, medicines, equipment or administrative support from Bayer HealthCare, received payment for lectures from Allergan and Novartis and has received support for conference attendance. GS acts as a consultant to Novartis, Bayer HealthCare, Allergan, Genentech, Roche, Heidelberg Engineering, Alcon, QLT and OD-OS. He also received support for travel to meetings from Bayer HealthCare, payment for lectures from Zeiss and is a patent holder in conjunction with Ocular Instruments, Inc. SH, TH and TB are employees of Bayer HealthCare. SS has received grants from Bayer HealthCare, Allergan and Novartis and acts as a consultant to Bayer HealthCare, Novartis and Allergan. She has also received support for travel to meetings, for participation in review activities and provision of writing assistance, medicines, equipment or administrative support from Bayer HealthCare and Novartis, received payment for lectures from Bayer HealthCare, Allergan and Novartis and has received support for conference attendance.

Patient consent Obtained.

Ethics approval Country IEC and IRB.

Provenance and peer review Not commissioned; externally peer reviewed.

Open Access This is an Open Access article distributed in accordance with the Creative Commons Attribution Non Commercial (CC BY-NC 3.0) license, which permits others to distribute, remix, adapt, build upon this work non-commercially, and license their derivative works on different terms, provided the original work is properly cited and the use is non-commercial. See: http://creativecommons.org/ licenses/by-nc/3.0/

\section{REFERENCES}

1 Ambati J, Fowler BJ. Mechanisms of age-related macular degeneration. Neuron 2012;75:26-39.

2 Slakter JS, Stur M. Quality of life in patients with age-related macular degeneration: impact of the condition and benefits of treatment. Surv Ophthalmol 2005;50:263-73.

3 Brown DM, Kaiser PK, Michels M, et al. Ranibizumab versus verteporfin for neovascular age-related macular degeneration. N Engl J Med 2006:355:1432-44.

4 Rosenfeld PJ, Brown DM, Heier JS, et al. Ranibizumab for neovascular age-related macular degeneration. N Engl J Med 2006;355:1419-31.

5 Abraham P, Yue H, Wilson L. Randomized, double-masked, sham-controlled trial of ranibizumab for neovascular age-related macular degeneration: PIER study year 2 . Am J Ophthalmol 2010:150:315-24.

6 Schmidt-Erfurth U, Eldem B, Guymer R, et al. Efficacy and safety of monthly versus quarterly ranibizumab treatment in neovascular age-related macular degeneration: the EXCITE study. Ophthalmology 2011;118:831-9.

7 Martin DF, Maguire MG, Fine SL, et al. Ranibizumab and bevacizumab for treatment of neovascular age-related macular degeneration: two-year results. Ophthalmology 2012;119:1388-98.

8 Busbee BG, Ho AC, Brown DM, et al. Twelve-month efficacy and safety of $0.5 \mathrm{mg}$ or $2.0 \mathrm{mg}$ ranibizumab in patients with subfoveal neovascular age-related macular degeneration. Ophthalmology 2013;120:1046-56.

9 Chakravarthy U, Harding SP, Rogers CA, et al. Ranibizumab versus bevacizumab to treat neovascular age-related macular degeneration: one-year findings from the IVAN randomized trial. Ophthalmology 2012;119:1399-411.

10 Holz FG, Amoaku W, Donate J, et al. Safety and efficacy of a flexible dosing regimen of ranibizumab in neovascular age-related macular degeneration: the SUSTAIN study. Ophthalmology 2011;118:663-71.

11 Gupta OP, Shienbaum G, Patel AH, et al. A treat and extend regimen using ranibizumab for neovascular age-related macular degeneration clinical and economic impact. Ophthalmology 2010;117:2134-40.

12 Toalster N, Russell M, Ng P. A 12-month prospective trial of inject and extend regimen for ranibizumab treatment of age-related macular degeneration. Retina 2013;33:1351-8 


\section{Clinical science}

13 Lucentis [summary of product characteristics]. Huningue, France: Novartis Pharma S.A.S., 2013

14 LUCENTIS $^{\text {TM }}$ (ranibizumab injection). Food and Drug Administration. http://www. accessdata.fda.gov/drugsatfda_docs/label/2013/125156s081/bl.pdf (accessed 13 Sep 2013)

15 Cohen SY, Mimoun G, Oubraham H, et al. Changes in visual acuity in patients with wet age-related macular degeneration treated with intravitreal ranibizumab in daily clinical practice: the LUMIERE Study. Retina 2013;33:474-81.

16 Cohen SY, Dubois L, Tadayoni R, et al. Results of one-year's treatment with ranibizumab for exudative age-related macular degeneration in a clinical setting. Am J Ophthalmol 2009;148:409-13.
17 Finger RP, Wiedemann P, Blumhagen F, et al. Treatment patterns, visual acuity and quality-of-life outcomes of the WAVE study-a noninterventional study of ranibizumab treatment for neovascular age-related macular degeneration in Germany. Acta Ophthalmol 2013;91:540-6.

18 Finger RP, Holz FG. Access to healthcare services for elderly patients with neovascular age-related macular degeneration. Ophthalmologe 2012;109:474-8.

19 Rotsos T, Patel PJ, Chen FK, et al. Initial clinical experience of ranibizumab therapy for neovascular age-related macular degeneration. Clin Ophthalmol 2010;4:1271-5.

20 Rofagha S, Bhisitkul RB, Boyer DS, et al. Seven-year outcomes in ranibizumabtreated patients in ANCHOR, MARINA, and HORIZON: a multicenter cohort study (SEVEN-UP). Ophthalmology 2013;120:2292-9. 